\title{
INTEGRATION OF DATA OF THE REMOTE SENSING, GIS, AND GAMMA- SPECTROMETRIC ANALYSIS TO STUDY SOIL MATERIAL REDISTRIBUTION
}

\author{
L. Trofimetz ${ }^{1, *}$, A. Kolesnikov ${ }^{2}$, E. Panidi ${ }^{3}$, P. Kikin ${ }^{3}$ \\ ${ }^{1}$ Orel State University named after I.S. Turgenev, Orel, Russia - trofimetc_1_n@mail.ru \\ ${ }^{2}$ Siberian State University of Geosystems and Technologies, Novosibirsk, Russia \\ ${ }^{3}$ Department of Cartography and Geoinformatics, Institute of Earth Sciences, Saint Petersburg State University, St. Petersburg, \\ Russia
}

KEY WORDS: Microrelief, Soil Runoff, Very High Resolution Imagery, GIS-based Mapping.

\begin{abstract}
:
The paper discusses a problem of complex data application when accounting erosion network elements to study soil runoff and soil material redistribution on arable slopes. It is needed to estimate and account contribution of microrelief landforms to the sediment (washed out soil material) redistribution on arable areas to enhance accuracy of estimation of the soil runoff and accumulation. However, microrelief landforms are hardly detected on topographic maps and plans used traditionally in land management. For example, temporary streams formed in plowing furrows (in the case of along-slope plowing) can be detected only when survey and soil sampling data are attracted, or (partially) using remote sensing data.

Due to such a context, we discover integrated analysis of map data (digital maps represented and processed in GIS environment), data of gamma-spectrometric analysis of the soil samples, and very high resolution satellite imagery, which is aimed onto detection of the role of stable and dynamically changing microrelief landforms in soil material redistribution.
\end{abstract}

\section{INTRODUCTION}

Study of soil erosion and particularly runoff and redistribution of the soil material is significant factor that impacts land management and land use activities. General understanding and correct estimation of these processes is significant also when organizing melioration and precision farming operations.

When the monitoring of the soil runoff in arable areas is not (or can not) be organized, the radiocaesium method (Golosov, Kvasnikova, 2000; Panidi et al., 2016, 2017; Saavedra, Mannaerts, 2005; Walling, He, 1999; Zapata, 2002) can help to study soil erosion and runoff processes. To study the features of the soil losses in an experimental agricultural field, a test plot was selected where (ancient) ravines of different size and (modern) streams formed in the plowing furrows are presented. Measurement of specific radioactivity of the Chernobyl origin caesium-137 in integral soil samples (collected on a $0-25 \mathrm{~cm}$ depth in the ravine thalwegs that have $23,000 \mathrm{~m}^{2}$ and $50,000 \mathrm{~m}^{2}$ catchment areas) allowed us to elaborate an equation series (Trofimetz et al., 2017, 2019) to model interdependences of caesium-137 radioactivity values, catchment area values (CostaCabral, Burges, 1994), and the relief profile curvature (Evans, 1972).

The study is conducted in central part of European Russia (Suhaya Orlitsa River basin, Orlovsky district of Oryol region Figures 1,2). This territory is characterized as having high risks of relief and soil erosion (Alifanov et al., 2010; Velichko, 2006; Berdnikov, 1976). Ground test plot (Figure 2) is located at the open arable slope having southern exposure. The soil in the area is classified as grey forest soil (Marusova, 2005).

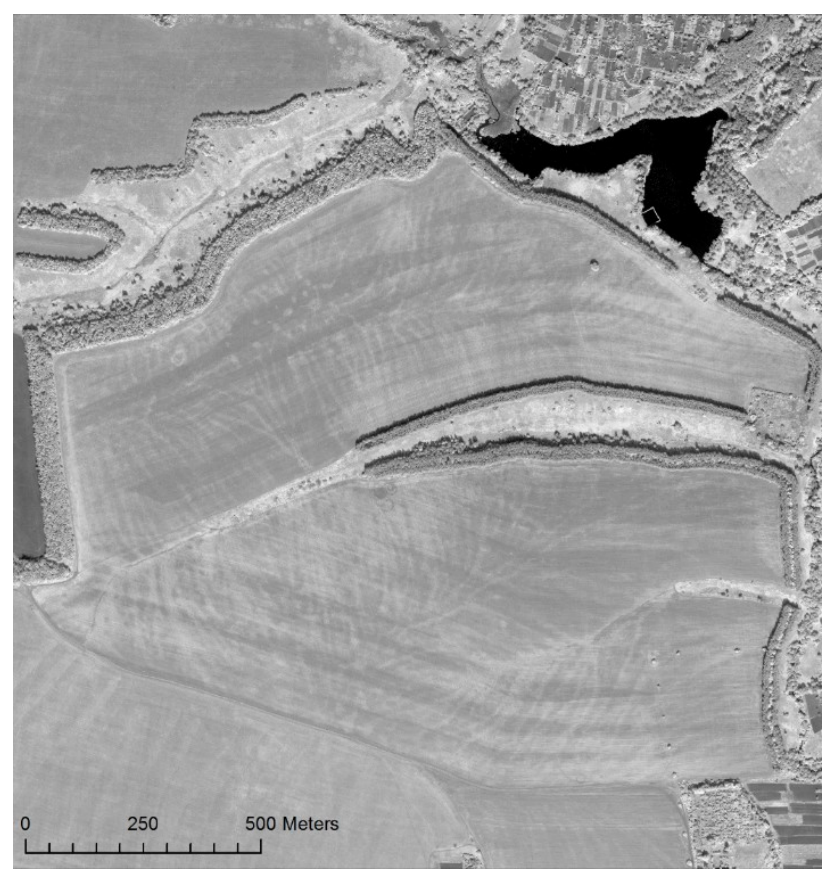

Figure 1. Satellite image of the study area (courtesy of the DigitalGlobe Foundation).

\footnotetext{
* Corresponding author
} 


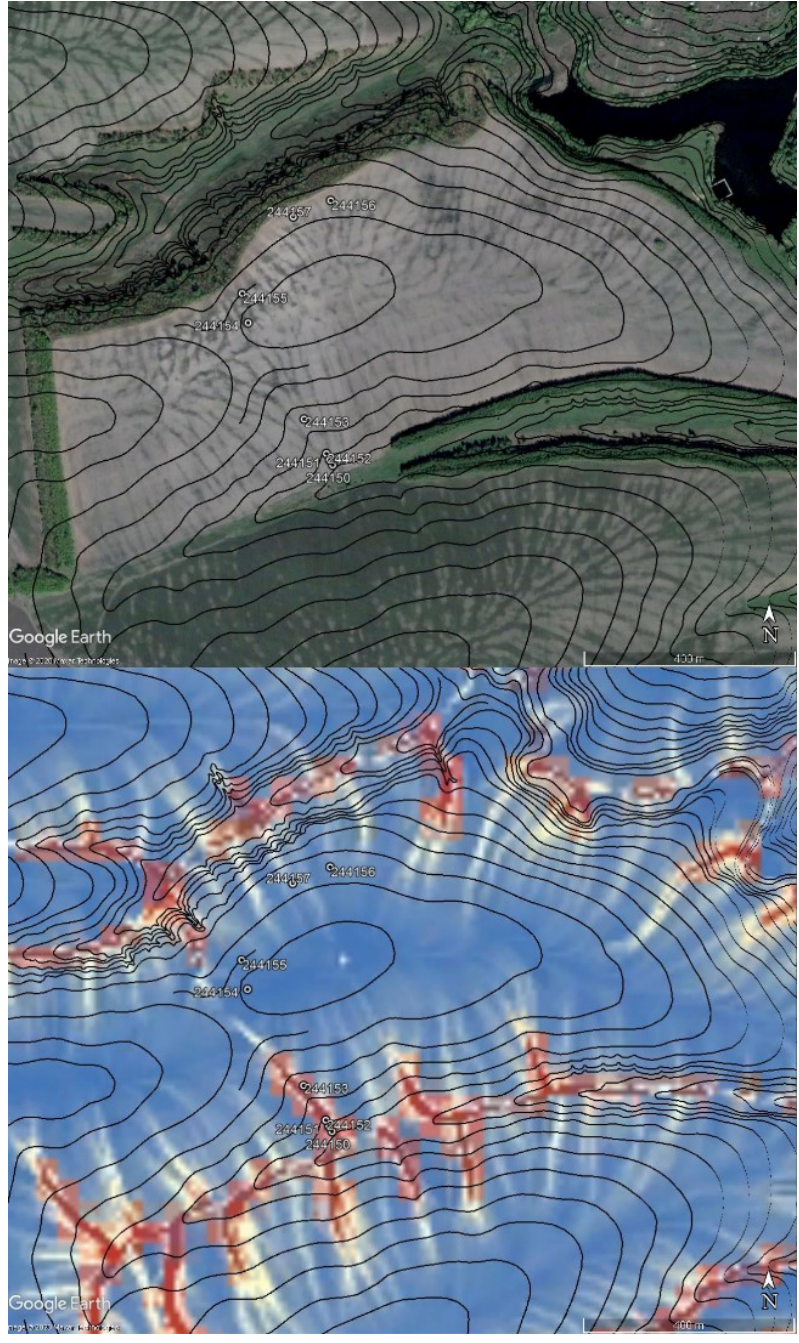

Figure 2. Fragment of the catchment area map (lower image) compared to the fragment of satellite image of the study area (upper image); black curves - relief contours; dark red stripes in the catchment area map indicate ancient ravine thalwegs); the data are visualized in Google Earth

\section{METHODOLOGY}

Existing recommendations on estimation of soil material redistribution in arable areas of upper parts of the drainage basins assume layer-by-layer on depth soil sampling (Belyaev et al., 2013; Gusarov et al., 2019; Owens, Walling, 1996; Sharifullin et al., 2018; Walling, He, 1997) followed by plotting the vertical distribution of caesium-137 radioactivity and allocation of the soil layers that mark the radioactivity of the soil material in 1986 (the year of the Chernobyl accident). In the case of spatial interpolation and estimation of slope morphometry influence onto the soil runoff, a comparative analysis have to be carried out for the slopes separated (zoned) by the exposure parameter. The ground test plot (area of arable slope and watershed) was zoned basing on morphometric conditions. Main zoning parameters were the profile curvature of the relief surface (convex slopes have positive or very small negative values of the profile curvature (Moore et al., 1993)), length of the slope, and catchment area. Zones were delineated basing on main ravines (streambeds) presented on the slope. Soil redistribution was estimated then in each zone (streambed) separately. Five zones were delineated. Relief parameters were computed and mapped basing on digital topographic maps.
Runoff and accumulation of the soil material were estimated basing on the soil sampling data. Soil sampling at the test plot was carried out in 2016. The samples were collected on whole 25 $\mathrm{cm}$ depth of arable soil layer at every $2 \mathrm{~cm}$ on depth. Samples were collected in the thalwegs of ravines and streams formed in the plowing furrows, and at the slopes in delineated zones. At the point of soil sampling a $0.8-1.0 \mathrm{~m}$ depth pit was excavated. A sampling areas of $0.1 \times 0.1 \mathrm{~m}$ were assigned in the pit wall to collect the samples.

Then the gamma-spectrometric analysis of the samples was provided, and (Chernobyl origin) caesium-137 deposit in the soil material was estimated. Gamma-spectrometry of soil samples was carried out in the Orlovsky Center of Chemization and Agricultural Radiology using the Gamma Plus universal spectrometric complex produced by CJSC STC Expertcenter (Moscow) basing on VNIIFTRI methodology (GP VNIIFTRI, 1996).

Finally, caesium-137 radioactivity was benchmarked (Shamshurina, 2016) and applied as a marker of soil runoff (Trofimetz et al., 2020). Additionally, caesium-137 radioactivity measurements were used to elaborate computational models that describe interdependencies between morphometric parameters of the microrelief and soil runoff amount in ton per hectare. These models are needed to provide lateral mapping of the soil runoff and accumulation. Whole number of collected soil samples was 200 approximately.

Satellite imagery were applied additionally as a control tool to delineated area of watershed and positions of temporary streams in the plowing furrows. Imagery interpretation was conducted in manual (visual) mode.

\section{SOIL RUNOFF ESTIMATION}

A detailed fragment of the satellite image of the ground test plot is shown in Figure 3. The main ravine has a north-eastern slope and collects sediments from the surrounding arable fields (from slope of northern exposure located to the south/south-east, and slope of the southern exposure located to the north/north-west). Points 4-7 in the image are the soil sampling points in the ravine thalweg, where samples were taken on depth of arable soil layer at every $2 \mathrm{~cm}$. More than 200 soil samples were collected.

The samples were subjected to gamma-spectrometric analysis. The depth of the detected peak radioactivity of caesium-137 (deposited in 1986) was used to estimate the amount of sediment delivery to the point during the 1986-2016. At point 5 (15416.5 in Figure 4), the depth of the caesium-137 radioactivity peak is $12 \mathrm{~cm}$. This depth value gave possibility to estimate the intensity of sediment delivery to the point as 44.4 ton per ha per year. The same amount of sediment delivery was obtained for point 7 . Thus, it was detected that all the sediments brought to the ravine in the area located between points 7 and 5 were buried on the slopes and in the bottom of the ravine in this area. Sediment delivery was estimated also as 96.5 and 37.0 ton per ha per year at the points 4 and 6 respectively. The delivery of sediments to point 4 formed mostly of the flow of soil material washed from the southern exposure slope. Delivery of sediments to the point 6 - from the northern exposure slope. Estimations of sediment delivery intensity at the points 4 and 6 were used also to assess the completeness of the for soil runoff accounting from the slopes. 


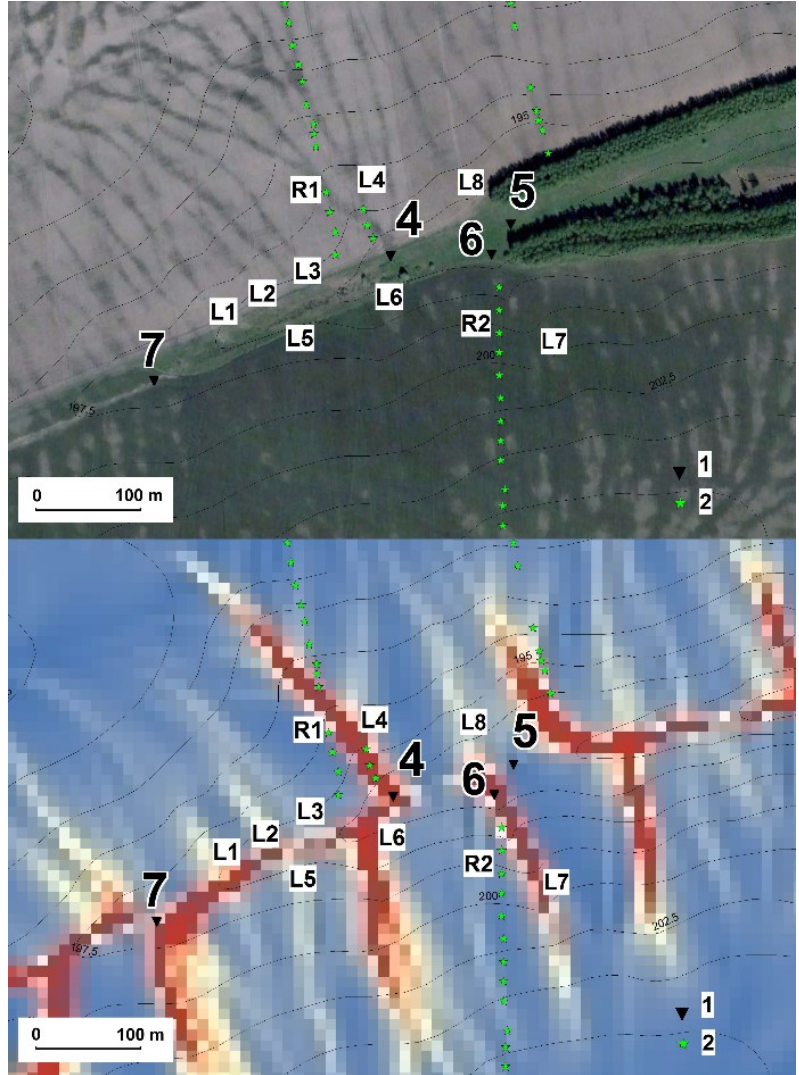

Figure 3. Fragments of satellite image (courtesy of the DigitalGlobe Foundation) of the ground test plot (upper image) and catchment area map (lower image) of the ground test plot; items 1 and 2 in the legends - soil sampling point locations (respectively discussed and not discussed in the paper text); L1-

L8 micro-ravine labels; R1, R2 modern stream labels.

Next equations were used to estimate sediment delivery for the slope parts where the profile curvature is positive (runoff zones):

$$
\begin{aligned}
& U=-0.0004 X+146.00 \\
& U=-0.0022 X+152.95 \\
& U=-0.0011 X+176.60 \\
& R=10 \cdot B \cdot Z /\left(t-t_{0}\right) \cdot\left(\frac{U}{U_{0}}-1\right) \\
& R=R_{m} \cdot 10000 \cdot 1110
\end{aligned}
$$

where $\quad U=$ caesium-137 specific radioactivity $(\mathrm{Bq} / \mathrm{kg})$ $X=$ catchment area $\left(\mathrm{m}^{2}\right)$

$R=$ soil runoff intensity (ton per ha per year) $B=$ soil material density (grey forest soil $\left.-1110 \mathrm{~kg} / \mathrm{m}^{3}\right)$ $Z=$ depth of the soil sampling $(0.25 \mathrm{~m})$ soil sampling $(t)$

$\left(t-t_{0}\right)=$ number of years between $1986\left(t_{0}\right)$ and year of

$U_{0}=$ caesium-137 specific radioactivity $(\mathrm{Bq} / \mathrm{kg})-$ reference (background) value detected at the watershed per year)

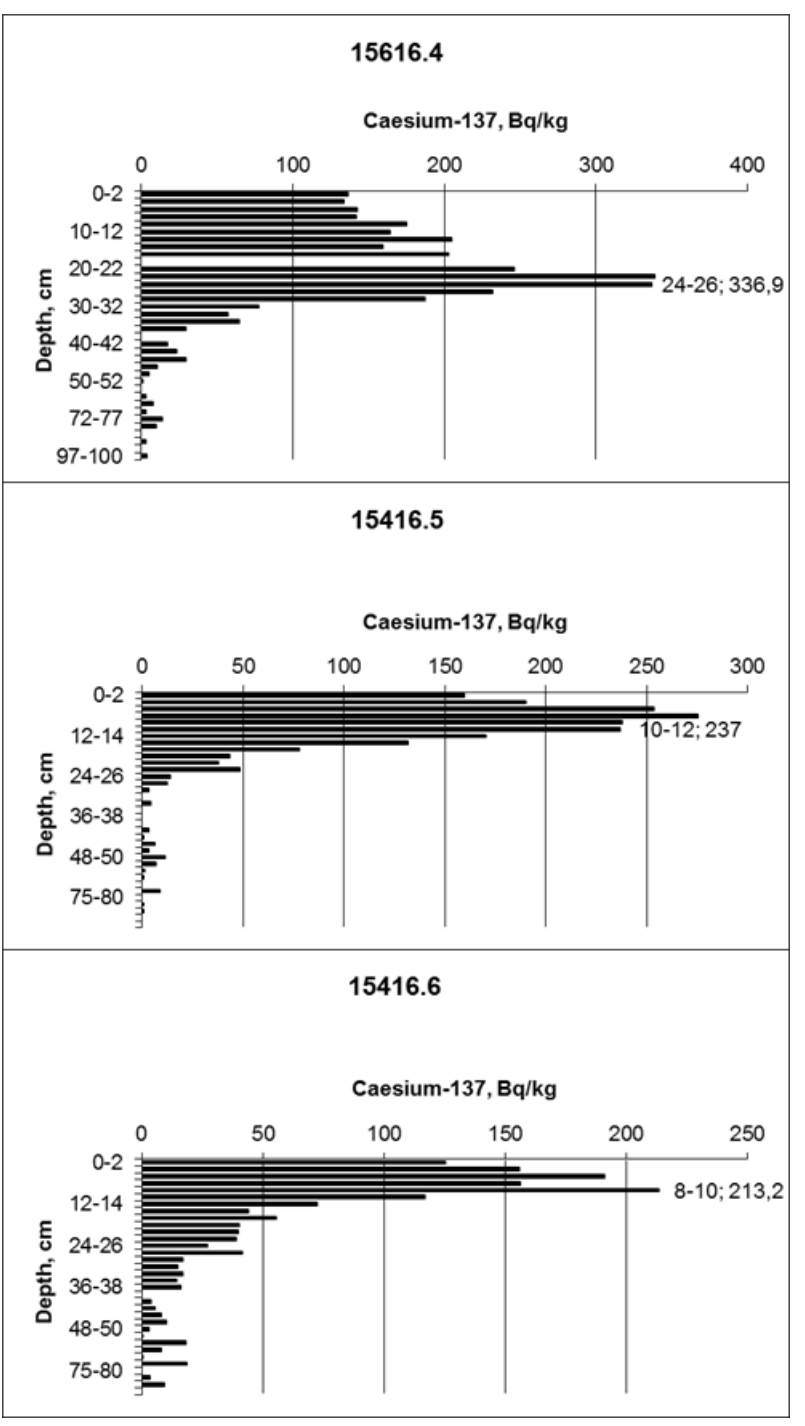

Figure 4. Plots of caesium-137 specific radioactivity observed on depth of the soil layer at sampling points 4 (plot 15616.4), 5 (plot 15416.5), and 6 (plot 15416.5).

\section{SOIL RUNOFF FROM SOUTHERN EXPOSURE SLOPE}

The equations 1-3 were elaborated as linear regression for the up to $50,000 \mathrm{~m}^{2}$ catchment area ravines (equation 1) and for the up to $23,000 \mathrm{~m}^{2}$ catchment area ravines (equations 2 and 3), while equation 2 is designed for the slope of out southern exposure and equation 3 for the slope of northern exposure. The equations derived from measurements of the specific radioactivity of caesium-137 in integral soil samples collected in the ravine thalweg on a $0-25 \mathrm{~cm}$ arable horizon depth. The samples were taken in thalwegs due to that the thalweg is well recognized usually both on the ground (in situ) and in very high resolution satellite imagery. The dependences are based upon the catchment area values at the sampling points (estimated using the DEMON method (Costa-Cabral, Burges, 1994)), the sign of the relief profile curvature, and the caesium-137 specific radioactivity measurements.

A detailed fragment of the catchment area map is shown in Figure 3. The map helps to define boundaries of the watersheds for the ravines. It can be seen that the micro-ravines are clearly distinguished by shades from brown to light blue. The inter- 
ravine watersheds correspond to the minimum local values of the catchment area (the dividing line was drawn through the points where the values of the catchment area are minimal).

While the caesium-137 specific radioactivity was measured in the thalwegs of ravines L4 and L6 only, the soil runoff estimation for the ravines L1, L2, L3, and L8 was carried out according to the equation 2 (obtained for up to $23,000 \mathrm{~m}^{2}$ catchment area, for the southern exposure slope). The catchment area values were derived from catchment area map for each ravine, and the expected caesium-137 specific radioactivity values were computed. Caesium-137 specific activity values in the thalwegs of streams R1 and R2 (formed in the plowing furrows) were estimated directly upon gamma-spectrometric analysis of integral soil samples (collected on a $0-25 \mathrm{~cm}$ depth). According to these data and the reference value of the caesium-137 radioactivity estimated at the watershed of the southern exposure slope (Trofimetz et al., 2020), soil runoff intensity was estimated according to equation 4 for the ravines L1, L2, L3, L4, L8 and for the stream R1 allocated at the southern exposure slope.

At point 4 located at the base of the slope (in the thalweg of main ravine), the sediment flow from a large $\left(47,000 \mathrm{~m}^{2}\right.$ catchment area) L4 ravine is collected. Data on sediment delivery intensity from the slope of the southern exposure were obtained here basing upon the soil sampling (plot 15616.4 in Figure 4). Comparison of the sediment delivery intensity to point 4 (estimated by equation 5) with the amount of soil runoff from the ravine L4 (estimated by equations 1 and 4) revealed their difference. L4 soil runoff intensity was estimated as 25.2 ton per ha per year, while the sediment delivery at the point 4 was 96.5 ton per ha per year.

It is clearly seen in the satellite image (Figure 3 ), that sediments are delivered to point 4 both along the ravine L4 and along the above-located ravines L1, L2 and L3. Also, the stream R1 delivers sediments to the point 4 . Summarizing of estimated soil runoff intensities $(17.4,18.8,16.3,25.2$, respectively for the ravines L1, L2, L3, L4) produces the amount of 77.7 ton per ha per year. Soil runoff intensity in the stream R1 is estimated as 20 ton per ha per year, so a total sediment delivery of 97.7 ton per ha per year can be obtained that is close to the value of the actually measured intensity of soil accumulation at point 4 (96.5 ton per ha per year). So it became possible to reduce the residual of sediment delivery estimation at point 4 to 1.2 ton per ha per year. This value suggests that the equation developed for up to $23,000 \mathrm{~m}^{2}$ catchment area ravines is well applicable to unexplored ravines.

The computations show also that the sediment volume received along the thalweg of the R1 stream is comparable to the volume of sediment carried along the L2 ravine (catchment area of 6350 $\mathrm{m}^{2}$ ). Additional accounting of sediment delivery along the L8 ravine (17.1 ton per ha per year) allowed us to estimate the average annual volume of sediment received from the slope of the southern exposure along the ravines L1, L2, L3, L4, L8 and the stream R1 during the period from 1986 to 2016 as 114.8 ton per ha per year.

\section{SOIL RUNOFF FROM NORTHERN EXPOSURE SLOPE}

To determine the volume of soil material washed into the main ravine that is deposited in the ravine slopes and does not reach point 5 , it was necessary to execute additional computations and to estimate micro-ravines that deliver sediment from the northern exposure slope (L5, L6, L7). Maximum value of caesium-137 radioactivity at point 6 was detected at a $10 \mathrm{~cm}$ depth. The intensity of sediment accumulation (delivery) estimated according to the equation 5 is 37.0 ton per ha per year.

The equation 3 was developed for the micro-ravines of the northern exposure slope (up to $23,000 \mathrm{~m}^{2}$ catchment area) to estimate caesium-137 radioactivity. The equation is based upon the results of analysis of the integral soil samples collected in the thalweg of the L7 ravine. Determination of the caesium-137 specific radioactivity of soil samples and elaboration of the equation 3 allowed us to proceed to the soil runoff intensity estimation according to equation 4.

The equation was applied to estimate sediment delivery in the ravines L5 and L7 located at the slope of northern exposure. Estimation results (Table 1) show that L5 ravine received 4.3 ton per ha per year, ravine L6 - 15.8 ton per ha per year, and the ravine $\mathrm{L} 7-14.2$ ton per ha per year.

\begin{tabular}{|l|c|c|c|}
\hline Location & $\begin{array}{c}\text { Catchment } \\
\text { area, } \mathrm{m}^{2}\end{array}$ & $\begin{array}{c}\text { Caesium-137 } \\
\text { specific } \\
\text { radioactivity, } \\
\text { Bq/kg }\end{array}$ & $\begin{array}{c}\text { Soil runoff/sediment } \\
\text { delivery intensity, } \\
\text { ton per ha per year }\end{array}$ \\
\hline L1 & 5200 & 141.51 & -17.4 \\
L2 & 6350 & 138.98 & -18.8 \\
L3 & 4200 & 143.71 & -16.3 \\
L4 & 47557 & 126.98 & -25.2 \\
L5 & 4500 & 171.65 & -4.3 \\
L6 & 24897 & 149.21 & -15.8 \\
L7 & 22095 & 152.30 & -14.2 \\
L8 & 4917 & 142.13 & -17.1 \\
R1 & - & & -13.5 \\
R2 & - & & -25.2 \\
7 & - & & 44.4 \\
4 & - & & 96.5 \\
5 & - & & 44.4 \\
6 & - & & 37.0 \\
\hline
\end{tabular}

Table 1. Soil runoff from the slopes, and delivery of sediments to the main ravine.

Trough, ravine $\mathrm{L} 7$ forms the amount of sediments accumulated at point 6 actually. The analysis of the plot of on-depth caesium137 radioactivity distribution at point 6 (Figure 2) allowed us to determine the sediment amount accumulated at point 6 . It was 37.0 ton per ha per year. Only 14.2 ton per ha per year is delivered through the L7 ravine to point 6. "Missing" sediment volume (up to 37 ton per ha per year) is brought to the point 6 along the R2 stream (formed in the plowing furrow). So the sum of the sediment volumes delivered along the ravine L7 (14.2 ton per ha per year) and along the stream R2 (25.2 ton per ha per year) is equal to 39.4 ton per ha per year. This value differs from the estimated using analysis results of the layer-by-layer soil sample collected at point 6 (37.0 ton per ha per year). However, the difference is estimated as 2.4 ton per ha per year only $(6.5 \%)$. Thus, we found that the sediments delivery along the stream formed in the plowing furrow at the northern exposure slope is quite large ( $68.1 \%$ of the sediment volume estimated at point 6$)$. The sediment volume in the R2 stream (25.2 ton per ha per year) is 1.77 times greater than the sediment volume (14.2 ton per ha per year) carried into the main ravine along the $\mathrm{L} 7$ micro-ravine (up to $23,000 \mathrm{~m}^{2}$ catchment area).

Finally, we estimated a part of the sediment volume deposited at the slopes of the main ravine (not flushed to the Suhaya Orlitsa River. Our computations showed that in the area located between point 7 and point 5, a volume of 114.8 ton per ha per year was received from the southern exposure slope in 1986-2016. 
Contribution of the R1 stream (13.5 ton per ha per year) to the sediment volume received from the southern exposure slope in the area between point 7 and point 5 (114.8 ton per ha per year) is $11.8 \% .59 .5$ ton per ha per year was delivered to the main ravine from the northern exposure slope. Contribution of the R2 stream (25.2 ton per ha per year) to the sediment volume flushed from the northern exposure slope between point 7 and point 5 ( 59.5 ton per ha per year) is estimated as $42.4 \%$. In total, 174.3 ton per ha per year were received from both slopes in the area between point 7 and point $5.65 .9 \%$ of this volume were collected from the southern exposure slope and $34.1 \%$ brought from the northern exposure slope.

Sediment volume remain unchanged along the bottom of the main ravine (from point 7 to point 5 ). It is estimated as 44.4 ton per ha per year at point 7 and 44.4 ton per ha per year at point 5 . Consequently, in the area between point 7 and point 5 a volume of 174.3 ton per ha per year was deposited at the slopes and in the bottom. This amount composes $79.7 \%$ of the total sediment volume (218.6 ton per ha per year) washed from the arable slopes of main ravine and reached point No. 5 (sum of 174.3 ton per ha per year and 44.4 ton per ha per year). A sediment amount that was moved further along the ravine thalweg to the river was estimated as $20.3 \%$.

\section{CONCLUSIONS}

Basing on the analysis of the diagrams of layer-by-layer caesium137 distribution in the arable soil layer, we estimated the intensity of soil runoff in the period of 1986-2016. Comparison of the estimations of soil material runoff and sediment delivery in the erosion network in ground test area with the estimations of soil material accumulation at ending points of erosion network allowed us to conclude that it is needed to take into account contribution of temporary streams formed in the plowing furrows.

The equations elaborated for estimation of the caesium-137 radioactivity basing on the catchment area and profile curvature appear applicable when estimating the caesium-137 radioactivity in unexplored ravines. The delivery of sediments in modern streams formed in plowing furrows have to be accounted in the general model of sediment delivery from arable slopes.

These streams are not detected on topographic maps directly, but their contribution to the soil runoff varies up to 65.8 ton per ha per year. Accounting of this previously unaccounted soil runoff part allowed to reduce the estimation error of the sediment accumulation at the ending points of erosion network, when estimating basing on microrelief modeling and soil runoff computational model.

In the study area, in-streams sediment delivery at the slope of the southern exposure was estimated as $11.8 \%$, while at the slope of the northern exposure $-42.4 \%$ of the total volume of soil material runoff at the plowed slopes accumulated in the receiving ravine thalweg. The volume of the sediment delivered to the receiving ravine from the slope of southern exposure in the studied area was estimated as $65.9 \%$ of the total volume of sediment. Erosional forms on the slope of the northern exposure delivered $34.1 \%$ of total year sediment material to the receiving ravine. However, only $20.3 \%$ of the sediment material were flushed outside of the receiving ravine to the riverbed.

The computations carried out in the frames of our study would be impossible without the use of the set of tools and methods that incorporates layer-by-layer soil sampling, integral measurements of the specific caesium-137 radio activity in the arable soil layer, and computational models elaborated basing on the catchment area and profile curvature estimations. Satellite imagery and GISs allowed us to zone the study area and to provide correct accounting of the contribution of each erosion form to the formation of the sediment volume.

\section{ACKNOWLEDGEMENTS}

The study was supported partially by Russian Geographical Society.

Used satellite imagery are courtesy of the DigitalGlobe Foundation.

Gamma-spectrometry of soil samples was carried out in the Orlovsky Center of Chemization and Agricultural Radiology.

\section{REFERENCES}

Alifanov, V.M., Gugalinskaya, L.A., Ovchinnikov, A.Yu., 2010. Paleocryogenesis and soils variety at the center of the East European plain. GEOS, Moscow. 178. (In Russian)

Belyaev, V.R., Golosov, V.N., Markelov, M.V., Evrard, O., Ivanova, N.N., Paramonova, T.A., Shamshurina, E.N., 2013. Using Chernobyl-derived ${ }^{137} \mathrm{Cs}$ to document recent sediment deposition rates on the River Plava floodplain (Central European Russia). Hydrological Processes, 27(6), 807-821. doi:10.1002/hyp.9461

Berdnikov, V.V., 1976. Paleocriogenic microrelief of central part of the Russian plane. Moscow, Nauka. 126. (In Russian)

Costa-Cabral, M.C., Burges, S.J., 1994. Digital Elevation Model Networks (DEMON): a model of flow over hillslopes for computation of contributing and dispersal areas. Water $\begin{array}{lll}\text { Resources } & \text { Research, } & \text { 30(6), }\end{array}$ doi:10.1029/93WR03512

Evans, L.S., 1972 General geomorfometry, derivatives of altitude, and descriptive statistics. In: Chorley, R.J. (Ed.) Spatial Analysis in Geomorfology. Methuen \& Co., London. 17-90.

Golosov V.N., Kvasnikova E.V., 2000. Erosion impact onto inlandscape radionuclide migration. Radioactivity of nuclear explosions and accidents: proceedings of the international conference, April 24-26, 2000, Moscow, 1, 733-741. (in Russian)

Gusarov, A.V., Rysin, I.I., Sharifullin, A.G., Golosov, V.N., 2019. Assessment of contemporary erosion/sedimentation rates trend within a small cultivated catchment using the radiocaesium137 as a chronomarker (a case study from the Udmurt Republic, European Russia). Geomorfologiya, 2, 37-56. (In Russian) doi:10.31857/S0435-42812019237-56

Marusova, E.A., 2005. Influence of natural and anthropogenic factors onto the properties of arable gray forest soils of the southern Moscow region. Thesis, $\mathrm{PhD}$ in biology. (In Russian)

Moore I.D., Gessler P.E., Nielsen G.A., Peterson G.A., 1993. Soil attribute prediction using terrain analysis. Soil Science Society of America Journal, 57(2). 443-452.

Owens, P.N., Walling, D.E., 1996. Spatial variability of Caesium-137 inventories at reference sites: an example from two contrasting sites in England and Zimbabwe. Applied Radiation and Isotopes, 47(7), 699-707. doi:10.1016/0969-8043(96)000152 
Panidi E., Trofimetz L, Sokolova J., 2016. Application of phytoindication and radiocesium indicative methods for microrelief mapping. IOP Conference Series: Earth and Environmental Science, 34(1), 012024, 6. doi:10.1088/1755-1315/34/1/012024

Panidi E., Trofimetz L., Sokolova J., Kunaeva E., 2017. Largescale indicative mapping of soil runoff. International Archives of the Photogrammetry, Remote Sensing and Spatial Information Sciences, XLII-3/W2, 175-178. doi:10.5194/isprs-archivesXLII-3-W2-175-2017

Saavedra C., Mannaerts C.M., 2005. Erosion estimation in an Andean catchment combining coarse and fine resolution satellite imagery. Proceedings of the 31 st International Symposium on Remote Sensing of Environment, 1017, 4. Accessible at: http://www.isprs.org/proceedings/2005/isrse/html/papers/1017.p df

Shamshurina, E.N., Golosov, V.N., Ivanov, M.M., 2016. Spatiotemporal reconstruction of field of the Chernobyl origin ${ }^{137} \mathrm{Cs}$ deposit in the soil cover in basin of the Lokna river. Radiation biology, Radioecology, 56(4), 414-425. (In Russian)

Sharifullin, A.G., Gusarov, A.V., Golosov, V.N., 2018. Assessment of contemporary erosion/sedimentation trend within a small cultivated catchment in the Republic of Tatarstan (European Russia). Geomorfologiya, 3, 93-108. (In Russian) doi:10.7868/S0435428118030082

Trofietz, L.N., Panidi, E.A., Chaadaeva, N.N., Sankova, E.A., Ivaneha, T.L., Petelko, A.I., 2019. Estimation of soil loss in the thalwegs of natural-anthropogenic streams generated by heavy rainfall on arable slopes: application of satellite imagery, GIS and radiocaesium method. InterCarto, InterGIS Proceedings, 25(2), 217-231. (In Russian) doi:10.35595/2414-9179-2019-2-25-217231

Trofimetz, L.N., Panidi, E.A., Chaadaeva, N.N., Sankova, E.A., Ivaneha, T.L., Tyapkina, A.P., Petelko, A.I., Alexandrova, A.P., Ladnova, G.G., 2020. Determig the reference value of Cesium137 specific activity on arable slopes in the periglacial area of the Upper Oka basin: application of satellite images, GIS and soil agrochemical indicators. InterCarto, InterGIS Proceedings, 26(3), 170-183. (In Russian) doi:10.35595/2414-9179-2020-326-170-183

Trofimetz, L.N., Panidi, E.A., Ivanekha, T.L., Petelko, A.I., 2017. Estimation of erosion activity in the ravine complex of arable slopes. InterCarto, InterGIS Proceedings, 23(1), 323-332. (In Russian) doi:10.24057/2414-9179-2017-1-23-323-332

Velichko, A.A., 2006. Relict cryogenic morphosculpture of the Russian Plain, its scientific and applied significance. Reports of the USSR Academy of Sciences, 158 (5), 1078-1081. (In Russian)

GP VNIIFTRI, 1996. A methodology for measuring the activity of radionuclides in counting samples on a scintillation gammaray spectrometer using the Progress software. 41. (In Russian)

Walling D.E., He Q., 1999. Improved models for estimating soil erosion rates from cesium-137 measurements. Journal of Environmental Quality, 28(2), 611-622. doi:10.2134/jeq1999.00472425002800020027x

Walling, D.E., He, Q., 1997. Use of fallout ${ }^{137} \mathrm{Cs}$ in investigations of overbank sediment deposition on river floodplains. Catena 29(3-4), 263-282. doi:10.1016/S0341-8162(96)00072-0
Zapata F. (ed.), 2002. Handbook for the Assessment of Soil Erosion and Sedimentation using Environment Radionuclides. Kluwer Academic Publishers. 220. 